\title{
The dentition of a eugeneodontiform shark from the Lower Pennsylvanian of Derbyshire, UK
}

\author{
Michał Ginter \\ Acta Palaeontologica Polonica 63 (4), 2018: $725-735$ doi:https://doi.org/10.4202/app.00533.2018
}

The anterior part of a medium-sized shark surrounded by hundreds of ostracod shells was found at the end of the last century in a dark limestone nodule from the Kinderscoutian (Bashkirian, Pennsylvanian) near Carsington, Derbyshire (England, UK). The shark is a caseodontoid eugeneodontiform, most probably belonging to Campodus agassizianus. Its dentition is of the crushing type, highly heterodont, but the symphyseal tooth whorl, typical of the most of eugeneodontiforms, was not found. The teeth are symmetrical labio-lingually which is unique in this group. The analysis of the available data leads to the conclusion that neither the tooth whorls of "Campodus variabilis" sensu Eastman, nor the mandibular dentition of "Agassizodus variabilis" sensu St. John and Worthen represent the genus Campodus and that these specimens deserve a new, probably common, name.

Key words: Chondrichthyes, Eugeneodontiformes, Campodus, teeth, Carboniferous, Bashkirian, UK, England.

Michał Ginter [m.ginter@uw.edu.pl], Faculty of Geology, University of Warsaw, Al. Żwirki i Wigury 93, 02-089 Warszawa, Poland.

This is an open-access article distributed under the terms of the Creative Commons Attribution License (for details please see creativecommons.org), which permits unrestricted use, distribution, and reproduction in any medium, provided the original author and source are credited. 
